\title{
Performance Evaluation of Routing Protocols in MANETS
}

\author{
Humaira Nishat $^{1}$, Sake Pothalaiah ${ }^{2}$ and Dr. D.Srinivasa Rao ${ }^{3}$ \\ ${ }^{1}$ Department of Electronics and Communication Engineering, CVR College of \\ Engineering, Hyderabad, India. \\ huma_nisha@yahoo.com \\ ${ }^{2}$ Department of Electronics and Communication Engineering, MRP UGC, Jawaharlal \\ Nehru Technological University, Hyderabad, India. \\ pawan. s14@gmail.com \\ ${ }^{3}$ Department of Electronics and Communication Engineering, Jawaharlal Nehru \\ Technological University, Hyderabad, India. \\ dsraoece@jntuh.ac.in
}

\begin{abstract}
In wireless ad hoc networks mobile stations or nodes are free to move around. The transmission range of the nodes is fixed in mobile ad hoc networks (MANETs) whereas the network topology changes in a different fashion. Due to dynamic nature of network topology some of the network links are destroyed while some new links are established. The routing protocols developed for wired networks cannot be used efficiently for wireless networks. For wireless ad hoc networks there are a few new routing protocols suitable for the dynamically changing ad hoc wireless environment. In this paper we compare the performance of two on-demand routing protocols (AODV and DSR) in terms of QoS parameters such as throughput, minimum, maximum \& average delay and packet delivery ratio. We performed extensive simulations using NS-2 simulator using both conventional TCP and TCP Vegas traffic sources.
\end{abstract}

\section{Keywords}

AODV, DSR, MANET routing protocols, TCP \& TCP Vegas.

\section{INTRODUCTION}

Mobile networks are classified as infrastructure networks and Mobile ad hoc networks (MANETs) [1], [2]. In infrastructure mobile network, nodes have basestations or wired access points within their transmission range. In contrast, MANETs [1] are autonomous self-organized networks without support of infrastructure. Mobile stations in MANETs are free to move around. Because of the fixed transmission range of mobile terminals, the network topology changes dynamically resulting in network establishment and breaking of some existing network links.

For wired networks, routing protocols were developed with the assumption that the topology is static. Therefore such routing protocols may not serve efficiently in case of wireless ad hoc networks. Thus new routing protocols are developed for the dynamically changing [8] ad hoc wireless environment. The routing protocols of wireless ad hoc networks fall into two category (1) Table-driven and (2) On-demand [9].

1.Table driven routing protocol maintain consistent, up-to-date routing information from each node to all other nodes of the network. Each network node therefore maintains one or more routing table which stores the routes to all the other network nodes. When changes in topology 
International Journal of Wireless \& Mobile Networks (IJWMN) Vol. 3, No. 2, April 2011

[8] occurs, the related information is sent to all network nodes in order to provide up-to-date routing information. Table driven routing protocol have the disadvantage of increased signaling traffic and power consumption as the routing information is disseminated to all the network nodes.

2.On-demand routing protocol follow a different approach. A route is established only when there is a need to for a network connection. When a source node $X$ needs a connection to a destination $\mathrm{Y}$, it invokes a routing discovery protocol to find a route connecting it to $\mathrm{Y}$. Once the route establishment is done, nodes $\mathrm{X} \& \mathrm{Y}$ and all the intermediate nodes store the information regarding the route from $\mathrm{X}$ to $\mathrm{Y}$ in their routing tables. The route is maintained until the destination is unreachable or the route is no longer needed. On-demand routing protocols have lower power consumption and less control signaling however, it has long end-to-end connection delay as the connection is established only upon the generation of a network connection required. In wireless ad hoc networks routing protocols are developed assuming that all stations have identical capabilities and employ the capability to perform routing related tasks such as route discovery/establishment and route maintenance in the network.

Several performance evaluation of routing protocols in MANETs have been performed using CBR traffic. Biradar, S.R. et al [10] have analyzed the AODV and DSR protocol using Group mobility model and CBR traffic sources. According to [10] DSR performs better in high mobility and DSR gives better average delay. Rathy R.K. et al [11] compared AODV and DSR routing protocols under random way point mobility model with TCP and CBR traffic sources. According to [11] AODV outperforms DSR in high mobility and/or high load situations. Harminder S.B. et al[12] investigated the performance of AODV and DSR routing protocol under group mobility models. According to [12] DSR gives better results in TCP traffic and under restricted bandwidth condition.

In this paper we have investigated the performance of on-demand routing protocols such as $\mathrm{Ad}$ hoc on demand distance vector (AODV)[3] and Dynamic source routing (DSR)[4] routing protocols in the scenario of Random Mobility Model using both conventional TCP and TCP Vegas traffic sources. The objective of the work is to understand the working mechanisms and to investigate which routing protocol gives better performance when TCP and TCP Vegas are used as the traffic source.

The rest of the paper is organized as follows. Section 2 gives a brief introduction of both AODV and DSR routing protocols. Section 3 tells about the simulation setup. Section 4 gives the results and performance comparison of the routing protocols. Finally, section 5 concludes the paper.

\section{DESCRIPTION OF ROUTING PROTOCOLS}

\subsection{Ad hoc on demand distance vector (AODV)}

Ad hoc on demand distance vector (AODV) [3] routing protocol creates routes on-demand. In AODV, a route is created only when requested by a network connection and information regarding this route is stored only in the routing tables of those nodes that are present in the path of the route.

The procedure of route establishment is as follows. Assume that node $\mathrm{X}$ wants to set up a connection with node $\mathrm{Y}$. Node $\mathrm{X}$ initiates a path discovery process in an effort to establish a route to node $\mathrm{Y}$ by broadcasting a Route Request (RREQ) packet to its immediate neighbors. Each RREQ packet is identified through a combination of the transmitting node's IP address and a broadcast ID. The latter is used to identify different RREQ broadcasts by the same node and is 
International Journal of Wireless \& Mobile Networks (IJWMN) Vol. 3, No. 2, April 2011

incremented for each RREQ broadcast. Furthermore, each RREQ packet carries a sequence number which allows intermediate nodes to reply to route requests only with up-to-date route information. Upon reception of an RREQ packet by a node, the information is forwarded to the immediate neighbors of the node and the procedure continues until the RREQ is received either by node $\mathrm{Y}$ or by a node that has recently established a route to node $\mathrm{Y}$. If subsequent copies of the same RREQ are received by a node, these are discarded.

When a node forwards a RREQ packet to its neighbors, it records in its routing table the address of the neighbor node where the first copy of the RREQ was received. This helps the nodes to establish a reverse path, which will be used to carry the response to the RREQ. AODV supports only the use of symmetric links. A timer starts running when the route is not used. If the timer exceeds the value of the 'lifetime', then the route entry is deleted.

Routes may change due to the movement of a node within the path of the route. In such a case, the upstream neighbor of this node generates a 'link failure notification message' which notifies about the deletion of the part of the route and forwards this to its upstream neighbor. The procedure continues until the source node is notified about the deletion of the route part caused by the movement of the node. Upon reception of the 'link failure notification message' the source node can initiate discovery of a route to the destination node.

\subsection{Dynamic Source Routing (DSR)}

Dynamic Source Routing (DSR) [4] uses source routing rather than hop-by-hop routing. Thus, in DSR every packet to be routed carries in its header the ordered list of network nodes that constitute the route over which the packet is to be relayed. Thus, intermediate nodes do not need to maintain routing information as the contents of the packet itself are sufficient to route the packet. This fact eliminates the need for the periodic route advertisement and neighbor detection packets that are employed in other protocols. The overhead in DSR is large as each packet must contain the whole sequence of nodes comprising the route.

DSR comprise the processes of route discovery and route maintenance. A source node wishing to set up a connection to another node initiates the route discovery process by broadcasting a RREQ packet. This packet is received by neighboring nodes which in turn forward it to their own neighbors. A node forward a RREQ message only if it has not yet been seen by this node and if the nodes address is not part of route. The RREQ packet initiates a route reply packet (RREP) upon reception of the RREQ packet either by the destination node or by an intermediate node that knows a route to the destination. Upon arrival of the RREQ message either to the destination or to an intermediate node that knows a route to the destination, the packet contains the sequence of nodes that constitute the route. This information is piggybacked on to the RREP message and consequently made available at the source node. DSR supports both symmetric and asymmetric links. Thus, the RREP message can be either carried over the same path with original RREQ, or the destination node might initiate its own route discovery towards the source node and piggyback the RREP message in its RREQ.

In order to limit the overhead of these control messages, each node maintains a cache comprising routes that were either used by these nodes or overheard. As a result of route request by a certain node, all the possible routes that are learned are stored in the cache. Thus, a RREQ process may result in a number of routes being stored in the source node's cache.

Route maintenance is initiated by the source node upon detection of a change in network topology that prevents its packet from reaching the destination node. In such a case the source node can either attempt to use alternative routes to the destination node or reinitiate route discovery. Storing in the cache of alternative routes means that route discovery can be avoided 
when alternative routes for the broken one exist in the cache. Therefore route recovery in DSR can be faster than any other on-demand routing protocols.

Since route maintenance is initiated only upon link failure, DSR does not make use of periodic transmissions of routing information, resulting in less control signaling overhead and less power consumption at the mobile nodes.

\section{SIMULATION SETUP}

We have used network simulator version 2.34 for the evaluation of our work. The NS-2 simulator software was developed at the University of California at Berkeley and the Virtual Inter Network testbed (VINT) project fall 1997[5],[6]. We have used Ubuntu 9.04 Linux environment. Our simulation setup [9] is a network with randomly placed nodes within an area of $1315 \mathrm{~m} * 572 \mathrm{~m}$. We have chosen a wireless channel with a two-way ground propagation model with a radio propagation model of $250 \mathrm{~m}$ and interference range of $550 \mathrm{~m}$. The parameters used for carrying out simulation are summarized in the table 1.

Table 1. Simulation Parameters

\begin{tabular}{|l|l|}
\hline Parameter & Value \\
\hline Routing Protocols & AODV,DSR \\
\hline MAC Layer & 802.11 \\
\hline Terrain Size & $1315 \mathrm{~m} * 572 \mathrm{~m}$ \\
\hline No. of Nodes & 25 \\
\hline Mobility Model & Random Mobility Model \\
\hline Packet Size & $1500 \mathrm{~B}$ \\
\hline Bandwidth & $11 \mathrm{MB}$ \\
\hline Frequency & $2.472 \mathrm{GHz}$ \\
\hline Antenna Type & Omni antenna \\
\hline Propagation Model & $2-$ Ray ground \\
\hline Speed & $0-5-10-15-20-25 \mathrm{~m} / \mathrm{s}$ \\
\hline Simulation Time & $100 \mathrm{~s}$ \\
\hline Traffic Source & TCP, TCP Vegas \\
\hline Application Layer & FTP \\
\hline
\end{tabular}

The node's speed is varied from 0 to $25 \mathrm{~m} / \mathrm{s}$ generated by uniform distribution. The simulation execution time is 100s. We have simulated the scenario with both the conventional TCP and TCP Vegas traffic sources. The aim of our simulation is to evaluate the performance differences of the two on-demand routing protocols and compare it with both TCP and TCP Vegas.

\subsection{Performance metrics}

Manet routing protocols can be evaluated by a number of quantitative metrics described by RFC2501 [7]. We have used the following metrics for evaluating the performance of the two routing protocols (AODV \& DSR). 


\subsubsection{Packet Delivery Fraction}

It is the ratio of the number of packets received by the destination to the number of data packets generated by the source.

\subsubsection{Minimum Delay}

It is defined as the minimum time taken for a data packet to be transmitted across a MANET from source to destination.

\subsubsection{Maximum Delay}

It is defined as the maximum time taken for a data packet to be transmitted across a MANET from a source to destination.

\subsubsection{Average end-to-end delay}

It is defined as the average time taken by the data packets to propagate from source to destination across a MANET. This includes all possible delays caused by buffering during routing discovery latency, queuing at the interface queue, and retransmission delays at the MAC, propagation and transfer times.

\subsubsection{Throughput}

It is the rate of successfully transmitted data packets per second in the network during the simulation.

\section{SIMULATION RESULTS}

Here we present a comparative analysis of the performance metrics of both the on-demand routing protocols AODV and DSR with both TCP and TCP Vegas traffic sources for different node speeds 5,10,15,20 \& 25m/s.

\subsection{Packet Delivery Fraction}

In case of TCP traffic source at low node velocity i.e., from 0 to $15 \mathrm{~m} / \mathrm{s}$ DSR performs better than AODV. But as the speed increases to $20 \mathrm{~m} / \mathrm{s}$ both DSR and AODV performs equally under all assumed load condition. With TCP Vegas, DSR gives more PDF than AODV at both low as well as high node velocities (Fig1). At low velocities AODV is comparable to DSR but the ratio decreases as the speed of node increases. Thus we conclude that AODV with TCP Vegas is comparable to DSR at low velocities of node but at high node velocities DSR performs better.

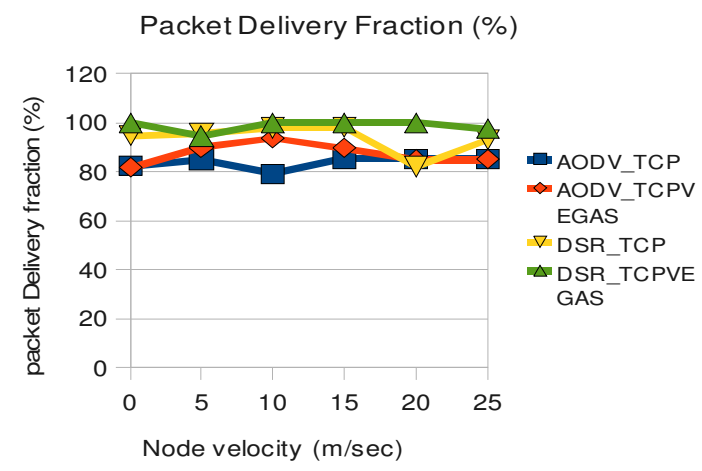

Figure 1. Packet Delivery Fraction 


\subsection{Minimum Delay}

In case of TCP traffic source, minimum end-to-end delay of AODV is better than DSR. As the velocity of node increases to $25 \mathrm{~m} / \mathrm{s}$ DSR has maximum delay. Thus AODV outperforms DSR. Comparing AODV with conventional TCP and TCP Vegas, at low speeds from 0 to $15 \mathrm{~m} / \mathrm{s}$ both traffic sources generates equal delay but as the speed increase to $25 \mathrm{~m} / \mathrm{s}$ AODV with TCP Vegas gives the minimum amount of delay which is $14 \mathrm{msec}$.

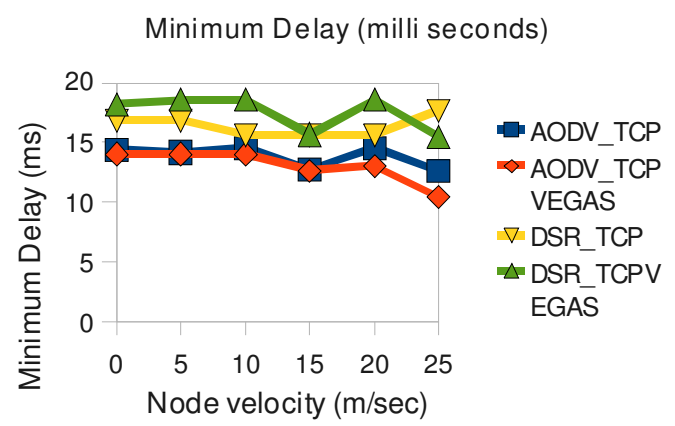

Figure2. Minimum Delay

\subsection{Maximum Delay}

With TCP traffic source AODV gives almost constant delay at all the speeds whereas delay of DSR increases almost linearly as the speed of node increases. DSR gives the maximum delay of $4 \mathrm{sec}$ at $25 \mathrm{~m} / \mathrm{s}$. With TCP Vegas traffic source both AODV and DSR has equal delay at $0 \mathrm{~m} / \mathrm{s}$ but as the node velocity increases to $5 \mathrm{~m} / \mathrm{s}$, delay of DSR increases abruptly to a high value and thereby remains constant till $25 \mathrm{~m} / \mathrm{s}$. Comparing conventional TCP and TCP Vegas traffic sources DSR gives almost equal delay till $20 \mathrm{~m} / \mathrm{s}$ but at $25 \mathrm{~m} / \mathrm{s}$ DSR with TCP gives a maximum delay of $4 * 10^{3} \mathrm{~m} \mathrm{sec}$. Thus AODV with TCP Vegas gives less delay thereby outperforming DSR.

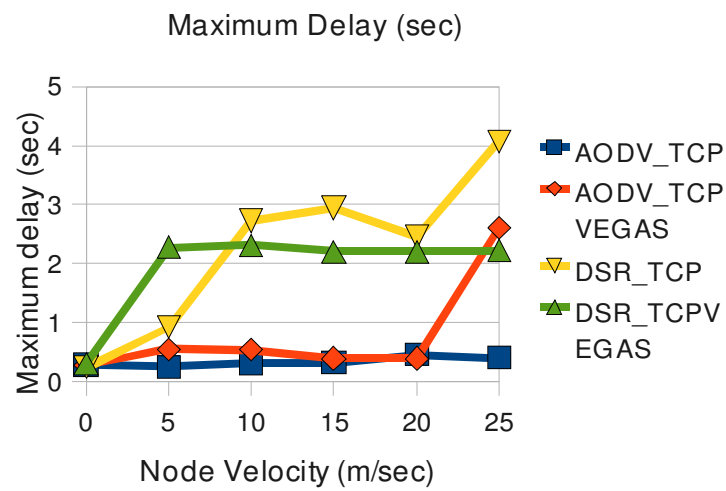

\subsection{Average Delay}

Figure3. Maximum Delay

In case of conventional TCP , AODV gives almost constant and least delay at all the node velocities whereas delay of DSR increases with the node velocity. In case of TCP Vegas also, AODV gives less delay than DSR.Thus the average end-to-end delay is least for AODV routing protocol with TCP Vegas traffic source. 


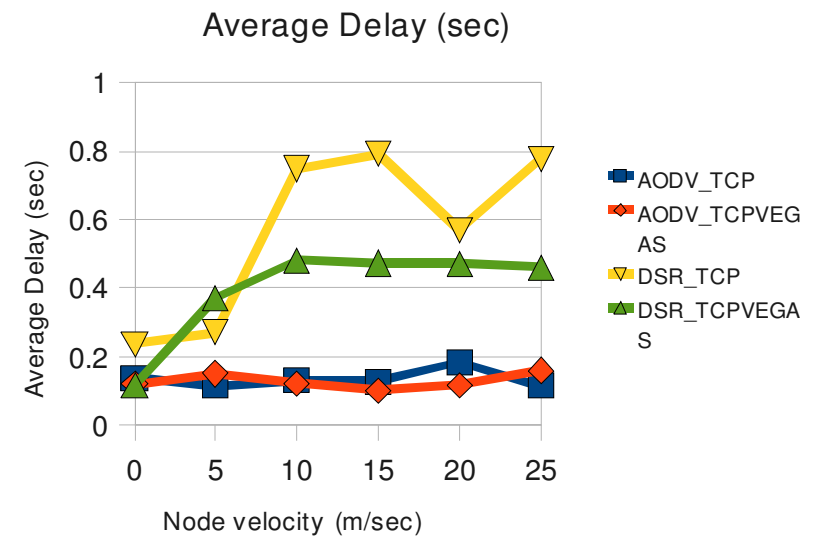

Figure 4.Average Delay

\subsection{Throughput}

In case of TCP traffic source, at $0 \mathrm{~m} / \mathrm{s}$ both DSR and AODV gives equal and maximum throughput. At 10m/s AODV gives less throughput than DSR but as the speed increases AODV outperforms DSR. With TCP Vegas traffic source, at $0 \mathrm{~m} / \mathrm{s}$ DSR gives more throughput than AODV but as the speed increases throughput of DSR decreases. Thus, AODV performs better than DSR as the speed increases. At low node velocities, AODV with both TCP \& TCP Vegas performs equally. But at higher velocities, AODV with conventional TCP gives better throughput performance than with TCP Vegas.

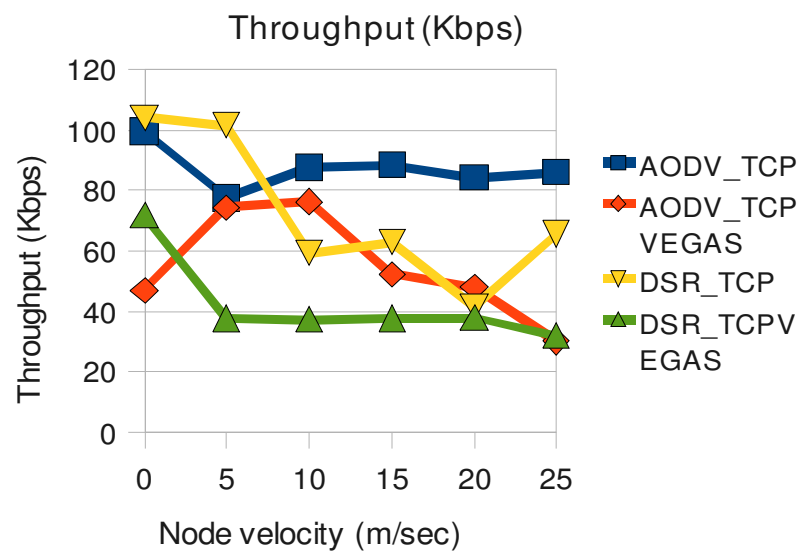

Figure5. Throughput

\section{CONCLUSIONS}

We have evaluated the two routing protocols AODV and DSR using both TCP \& TCP Vegas traffic sources. Based on the results we conclude that, both AODV and DSR gives almost same packet delivery fraction at low node velocities but as the velocity of the node increases DSR gives better PDF with TCP Vegas. Delay is maximum for DSR and minimum for AODV with TCP Vegas. Average end-to-end delay of AODV is less than DSR. Throughput of AODV is better than that of DSR. Thus, AODV with TCP Vegas traffic source outperforms DSR. 
International Journal of Wireless \& Mobile Networks (IJWMN) Vol. 3, No. 2, April 2011

In this paper the two routing protocols AODV \& DSR are analyzed and their performances have been evaluated with respect to five performance metrics using the two traffic sources TCP \& TCP Vegas. This paper can be enhanced by analyzing other MANET routing protocols with different traffic sources.

\section{REFERENCES}

[1] M.S. Carson, S. Batsell and J. Macker, “Architecture consideration for Mobile Mesh Networking," Proceedings of the IEEE Military Communications Conference(MILCOM), vol.1, pp 225-229, 21-24 oct.1996.

[2] C.K. Toh "Ad Hoc Mobile Wireless Networks Protocols and Systems", First Edition, Prentice Hall Inc, USA 2002.

[3] C.Perkins and E.Royer, “Ad Hoc On Demand Distance Vector Routing," Proceedings of the $2^{\text {nd }}$ IEEE workshop on Mobile Computing Systems and Applications(WMCSA 1999) pp.99-100, Feb-1999.

[4] D.B.Johnson, D.A.Maltz and J.Broch, "DSR: The Dynamic Source Routing Protocol for Multi-Hop Wireless Ad Hoc Networks”, Ad Hoc Networking, pp 139-172, 2001.

[5]UCB/LBNL/VINT Network Simulator, http://wwwmash.cs.berkeley.edu/ns/referred on March 2010.

[6] "The Network Simulator- ns-2", available at http://www.isi.edu/nsnam/ns/referred on march 2010.

[7] S.Corson and J.Macker, "Routing Protocol performance Issues and Evalaution Considerations", RFC2501, IETF Network Working Group, January 1999.

[8]N.H.Vaidya, "Mobile Ad Hoc Networks Routing, MAC and transport Issues", Proceedings of the IEEE International Conference on Computer Communication INFOCOM,2004.

[9] L.Layuan, Y.Peiyan and L.Chunlin, "Performance Evaluation and Simulations of Routing Protocols in Ad Hoc Networks" Computer Communications, vol.30, pp.1890-1998, 2007.

[10] S.R.Biradar, Hiren H.D.Sharma, Kalpana Sharma and Subir Kumar Sarkar, "Performance Comparison of Reactive Routing Protocols of MANETs Using Group Mobility Model", IEEE International Conference on Signal Processing Systems, pages 192-195, 2009.

[11] Suresh Kumar, R.K.Rathy and Diwakar Pandey, "Traffic Pattern Based Performance Comparison of Two Routing Protocols for Ad hoc Networks Using NS2", $2^{\text {nd }}$ IEEE International Conference on Computer Science and Information Technology, 2009.

[12] Harminder S.Bindra, Sunil K.Maakar and A.L.Sangal, "Performance Evaluation of Two Reactive Routing Protocols of MANET using Group Mobility Model", International Journal of Computer Science Issues, Vol.7, Issue 3, No.10, May 2010.

[13] Yasser Kamal Hassan, Mohammed Hashim Abd El-Aziz and Ahmed Safwat Abd El-Radi, "Performance Evaluation of Mobility Speed over MANET Routing Protocols", International Journal of Network Security, Vol.11, NO.3, pp.128-138, Nov 2010.

[14] X.Hong, M.Gerla, G.Pei and C.C.Chiang, "A Group Mobility Model for Ad Hoc Wireless Networks”, in ACM/IEEE MSWiM, August1999.

[15] M. Li, L. Zhang, V. O. K. Li, X. Shan and Y. Ren, “An Energy-Aware Multipath Routing Protocol for Mobile Ad Hoc Networks,” Proceedings of the ACM SIGCOMM Asia, April 2005.

[16] N. T. Javan and M. Dehghan, "Reducing End-to-End Delay in Multi-path Routing Algorithms for Mobile Ad hoc Networks," Proceedings of the International Conference on Mobile Ad hoc and Sensor Networks (MSN 2007), Lecture Notes in Computer Science (LNCS) 4864, pp. 703 - 712, December 2007. 
International Journal of Wireless \& Mobile Networks (IJWMN) Vol. 3, No. 2, April 2011

[17] S. Vijay, S. C. Sharma, V. Gupta and S. Kumar, "CZM-DSR: A New Cluster/Zone Disjoint MultiPath Routing Algorithm for Mobile Ad Hoc Networks," Proceedings of the IEEE International Advanced Computing Conference (IACC), Patiala, India, pp. 480 - 485, March 2009.

[18] I. S. Ibrahim, A. Etorban and P. J. B. King, "Multi-path Distance Vector Zone Routing Protocol for Mobile Ad hoc Networks: MDVZRP," Proceedings of the 9th Annual Postgraduate Symposium on The Convergence of Telecommunications, Networking and Broadcasting (PGET), June 2008.

[19] J. Zhang, C. K. Jeong, G. Y. Lee and H. J. Kim, "Cluster-based Multi-path Routing Algorithm for Multi-hop Wireless Network," International Journal of Future Generation Communication and Networking, Vol. 1, No. 1, pp. 67 - 74, December 2008.

[20] D. Shin and D. Kim, "3DMRP: 3-Directional Zone-Disjoint Multi-path Routing Protocol," IEICE Transactions on Information and Systems, Vol. E92-D, No. 4, pp. 620-629, April 2009.

[21] G. G. Md. N. Ali, R. Chakraborty, Md. S. Alam and E. Chain, "An Efficient Approach for Generalized Load Balancing in Multi-path Packet Switched Networks," AIRCC International Journal of Computer Networks and Communications, Vol. 2, No. 2, pp. 142-153, March 2010.

[22] N. Cooper and N. Meghanathan, "Impact of Mobility Models on Multi-path Routing in Mobile Ad hoc Networks," AIRCC International Journal of Computer Networks and Communications, Vol. 2, No. 1, pp. 185-174, January 2010.

[23] Natarajan Meghanathan, "Performance comparison of link, node and zone disjoint multi-path routing strategies and minimum hop single path routing for mobile ad hoc networks", AIRCC International Journal of Wireless \& Mobile Networks (IJWMN) Vol.2, No.4, November 2010

[24] R. Manoharan and E. Ilavarasan "Impact of Mobility on the Performance of Multicast Routing Protocols in Manets", AIRCC International Journal of Wireless \& Mobile Networks (IJWMN) Vol.2, No.2, May2010.

\section{Authors}

1. Humaira Nishat received the B-Tech degree in Electronics and Communication Engineering in the year 2000 and M-Tech degree in Digital Systems \& Computer Electronics in the year 2004 from Jawaharlal Nehru Technological University Hyderabad, India. She is currently working towards the $\mathrm{PhD}$ degree in the department of Electronics and Communication Engineering, Jawaharlal Nehru Technological University Hyderabad, India. Her research interests include Wireless Communications and Networks.

2. Sake Pothalaiah, graduated in the Department of ECE from National Institute of Technology Warangal in 2006, he obtained his M.E.(ECE) from University College of Engineering ,OU in 2008. He is now working as project associate MRP UGC. His area of interests include Ad hoc wireless networks woks, Image Processing, Control System and Bio Medical Signal Processing

3. Dr. D.Srinivasa Rao, received the B-Tech degree in Electronics and Communication Engineering from Nagarjuna University, India in 1986 and M.E degree in Digital Systems, Osmania University, India in 1994, Phd degree in Computer Networks from University of Hyderabad, India in 2004. He is currently working as Professor in the dept. of ECE, Jawaharlal Nehru Technological University Hyderabad, India.
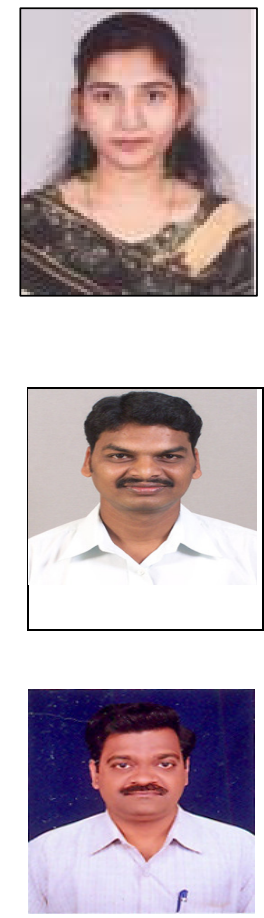